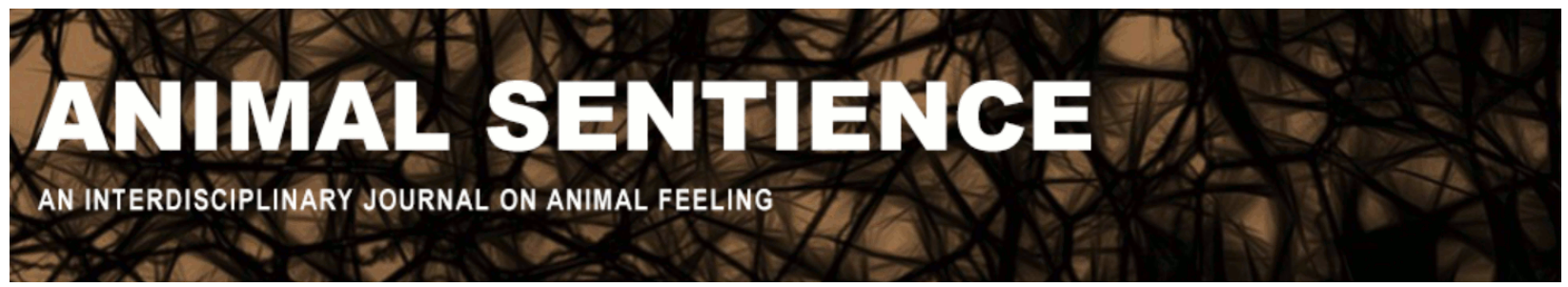

Gutfreund, Yoram (2019) Who needs a mind when you have thousands of fingers?. Animal Sentience 26(3)

DOI: $10.51291 / 2377-7478.1469$

Date of submission: 2019-05-31

Date of acceptance: 2019-06-05

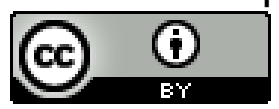

This article has appeared in the journal Animal

Sentience, a peer-reviewed journal on animal

cognition and feeling. It has been made open access,

free for all, by WellBeing International and deposited

in the WBI Studies Repository. For more information,

please contact

wbisr-info@wellbeingintl.org.

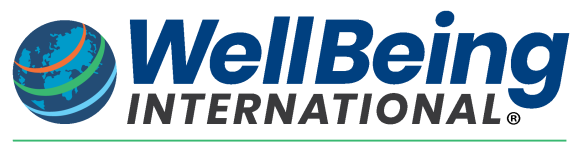

SOLUTIONS FOR PEOPLE, ANIMALS AND ENVIRONMENT 


\title{
Who needs a mind when you have thousands of fingers?
}

\author{
Commentary on Mather on Octopus Mind
}

\author{
Yoram Gutfreund \\ Department of Neurobiology \\ The Technion - Israel Institute of Technology
}

\begin{abstract}
Mather's target article aligns with a common tendency of granting the octopus a mind or consciousness. But what is the meaning of an octopus's mind? Is it part of nature or is it observer-dependent, imputed to satisfy our own psychological needs? In this commentary, I build on my own experience with octopuses to challenge the notion that we can conclusively attribute a mind to an animal; and I question the scientific usefulness of doing so.
\end{abstract}

Yoram Gutfreund, Associate Professor of
Neurobiology at the Faculty of Medicine of the
Technion, specializes in Neuroethology, the
comparative study of the neural basis of animal
behavior. His current research focuses on attention
behavior in birds. In the past, he studied motor
control of the octopus's flexible arms. Website

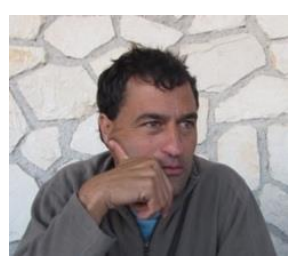

Octopuses are fascinating to any observer, and to some scientists they provide a unique case of convergent evolution. But to others, there is more to it than that. It is becoming popular for writers, philosophers and scientists to grant the octopus a mind or consciousness (of some sort). This prompted the inclusion of the octopus - the only invertebrate species - in The Cambridge Declaration on Consciousness, beating to the list its natural competitors, the fish (Bekoff 2012).

One intuitive rationale behind attributing a mind to octopuses stems from witnessing their unique ability to solve complex problems, such as opening boxes and escaping ingeniously from water tanks (Fiorito et al. 1990). I came across this 'escape-artistry' when I was a graduate student in the lab of Prof. Benny Hochner at the Hebrew University of Jerusalem. Aware of their infamous escaping reputation, we not only housed them in tanks sealed with thick transparent plexiglass covers, but we also included sticks with rubbers at both ends extending to shelves above to firmly press down on each cover. This ensured that the only way to remove the cover would be by pulling the stick sideways and only from the outside of the tank. Despite our confidence in our 'escapeproof' device, we discovered, one morning, an octopus roaming around the lab corridor. It turned out that the octopus managed to slide its flexible arm through a tiny crack between the cover, only to remove the stick sideways and escape the tank. This impressive feat could be (and typically is) a testimony to the animal's high cognitive ability to solve sequential problems.

However, there is an alternative and highly plausible explanation. Consider the following. The octopus has eight arms, each equipped with two rows of suction cups (about 300 per arm). A suction cup is the tip of a small muscular and flexible appendage that is covered with sophisticated mechano- and chemo-sensitive receptors. Each of the suction cups is controlled by its own little brain (suction ganglion + brachial ganglion) that collects and processes the local sensory inputs. to then control local muscular movements. Thus, every part along the arm is capable of functioning like an independent palm, allowing for an immensely efficient exploration and manipulation of the environment. When the octopus is in an exploratory state, the arms spread 
out to move along surfaces and explore. Once a suction cup encounters an object, a simple set of reflexes kicks in: attach, pull and push in every possible direction. Eventually, it will find a direction with the least resistance to which more force will be applied or to which nearby cups or additional $\operatorname{arm}(\mathrm{s})$ may be recruited for additional strength.

To return to our escaping octopus: During a random encounter of one of its arms with the cover, it managed to apply sufficient force to lift it ever-so-slightly so that another arm may have chipped in to apply more force to open it, allowing another arm that accidently hit the crack to squeeze through and, during the arm's exploration of the exterior of the tank, it (again accidently) met the stick to then wrap around and pull it away. With 2,400 such appendages working in parallel, it becomes clear how an octopus manages to open doors and jars in ways that are unfamiliar to us and with little help from its central brain.

It is important to note that I am not telling this story to downplay the octopus's intelligence or cognitive abilities. (I am also well aware that an anecdotal story cannot replace rigorous scientific evaluation, such as that provided by Mather 2019.) My intention here is to demonstrate the power of anthropomorphism and the problems associated with it. We begin with the observation of an octopus solving a complex problem; this builds our confidence in the octopus having some understanding and reasoning about the situation just as we do (i.e., a mind). However, after realizing that the dynamics of multiple simple and automatic elements inevitably lead to the desired outcome eventually, one's confidence in the octopus's subjective understanding and planning is reduced.

In octopuses, where much of the intelligence is distributed in the action of the arms, it is easy to see the underlying automatic dynamics at work; but what about other animals? Take, for example, a New Caledonian crow lifting a basket of food with a hook (Rutz et al. 2016) or a rat choosing to release a stressed companion from a cage (Ben-Ami Bartal, Decety, \& Mason 2011). What if we could tell the story about how these behaviors can be achieved by the mindless dynamics of multiple simple automatic neural elements? We cannot tell the story about the crow or the rat because we don't know it for sure and it is too complicated. But this does not help because we all agree that there is such a story underlying any behavior. Since this is so, based on what do we infer a mind or consciousness to an animal if not out of anthropomorphism?

Niko Tinbergen, the founder of ethology, objected to bringing up subjectivity in the scientific treatment of animal behavior (Tinbergen 1951, Vicedo 2017). His famous four questions do not include subjectivity. According to Tinbergen, mechanisms, evolution and development are sufficient (Bateson \& Laland 2013). Trying to fit in the animal's subjective point of view would not result in a better biological understanding or description of the behavior. However, the main objection stems from the recognition that a reference to an animal's subjectivity cannot be dissociated from the observer's own subjectivity, which would be scientifically deleterious.

In his book Curious Naturalists, Tinbergen (1984) describes behaviors of wasps, moths and gulls that are no less amazing and cognitive than the behaviors of octopuses, yet he didn't use illdefined words like mind, aware, understanding, knowing, etc. Reading the book, one remains stunned by the amazingly intelligent learning and behavioral capabilities of even the smallest and least expected animals - all the products of evolution. It teaches us that animals are always surprising and intelligent in the endless variety of ways in which they cope behaviorally with their environments, and that we can understand, admire and respect animals even without granting them a mind or consciousness of any kind. 


\section{References}

Bateson, P., \& Laland, K. N. (2013). Tinbergen's four questions: an appreciation and an update. Trends in Ecolology and Evolution 28(12): 712-718.

Bekoff, M. (2012). Animals are conscious and should be treated as such. New Scientist 215(2883): 24-25.

Ben-Ami Bartal, I., Decety, J., \& Mason, P. (2011). Empathy and pro-social behavior in rats. Science 334(6061): 1427-1430.

Fiorito, G., von Planta, C., \& Scotto, P. (1990). Problem solving ability of Octopus vulgaris lamarck (Mollusca, Cephalopoda). Behavioral and Neural Biology 53(2): 217-230.

Mather, J. (2019). What is in an octopus's mind? Animal Sentience 26(1).

Rutz, C., Sugasawa, S., van der Wal, J. E. M., Klump, B. C., \& St Clair, J. J. H. (2016). Tool bending in New Caledonian crows. Royal Society Open Science 3(8): 160439.

Tinbergen, N. (1951). The study of instinct. Oxford, The Clarendon Press.

Tinbergen, N. (1984). Curious naturalists. University of Massachusetts Press.

Vicedo, M. (2017). The 'Disadapted' animal: Niko Tinbergen on human nature and the human predicament. Journal of the History of Biology 51(2): 191-221. 